\title{
LASER AND PHYSICAL PROPERTIES OF BODIPY CHROMOPHORES IN NEW FLUORINATED POLYMERIC MATERIALS
}

\author{
O. García ${ }^{1 *}$, R. Sastre ${ }^{1}$, D. del Agua ${ }^{1}$, A. Costela ${ }^{2}$, I. García-Moreno ${ }^{2}$, F. López
} Arbeloa $^{3}$, J. Bañuelos Prieto ${ }^{3}$ and I. López Arbeloa ${ }^{3}$

${ }^{1}$ Instituto de Ciencia y Tecnología de Polímeros, C.S.I.C., Juan de la Cierva 3, 28006

Madrid, Spain. *Corresponding autor e-mail: ogarcia@ictp.csic.es, tel: +34-

915622900, fax: $+34-915644853$.

${ }^{2}$ Instituto de Química-Física “Rocasolano”, C.S.I.C., Serrano 119, 28006 Madrid, Spain.

${ }^{3}$ Departamento Química-Física, Universidad país Vasco-EHU, Apartado 644, 48080Bilbao, Spain.

\section{Supporting Information}

\section{Structural and physical characterization of new materials}

Molecular weights and molecular weight distributions were measured by Size Exclusion Chromatography (SEC) using a chromatography system (Waters Division Millipore) equipped with a Waters Model 410 refractive index detector. Tetrahydrofuran (THF) was used as an eluent at a flow rate of $1 \mathrm{~cm}^{3} / \mathrm{min}$. The operation temperature was $35^{\circ} \mathrm{C}$. Styragel-packed columns (HR1, HR3, HR4E, and HR5E, from Waters) were used. Calibration of the instrument was performed with standard samples 
of poly(methyl methacrylate) (PMMA, from Polymer Laboratories) in the range between $3.53 \times 10^{6}$ and $5 \times 10^{2} \mathrm{~g} / \mathrm{mol}$.

The glass transition temperature $\left(T_{\mathrm{g}}\right)$ of the matrices was measured by using a differential scanning calorimeter (DSC-6, Perkin Elmer). DSC scans of the materials as very fine powder were conducted under nitrogen atmosphere at a heating rate of 20 ${ }^{\circ} \mathrm{C} / \mathrm{min}$, from $20^{\circ} \mathrm{C}$ to $150{ }^{\circ} \mathrm{C}$ after maintaining the material in vacuum for 5 hours at 40 ${ }^{\circ} \mathrm{C}$ in order to remove the solvents occluded into the matrix.

All the Tg values obtained for the linear fluorinated matrices were around $80^{\circ} \mathrm{C}$, independent of the fluorinated monomer or the composition employed in the synthesis. While, and as expected, highest Tg are obtained in the crosslinked matrices but no a clear tendency with the grade of crosslinking were obtained, these results suggest the possibility of remained double bonds without suffer reaction of polymerization in the matrices. In fact, when the crosslinked matrices were recorded at higher temperatures, from $20^{\circ} \mathrm{C}$ to $250^{\circ} \mathrm{C}$ an exothermic pick was detected in each of them due to the reaction of the remained double bonds. A second thermal recording $24 \mathrm{~h}$ after this thermal treatment up to $250^{\circ} \mathrm{C}$ confirms the increase of the $\mathrm{Tg}$ values, a direct consequence of the increase in the rigidity of the medium due to a higher crosslinked density reached with the temperature.

Densities of the different materials were determined using a gravimetric method of the samples. Refractive indices of the prepared samples were measured at room temperature using an Abbe refractometer (Zeiss) employing 1-bromonaphtalene as sample-support interphase and a sodium lamp as incident light at $589 \mathrm{~nm}$. Oxygen permeation was measured at $30{ }^{\circ} \mathrm{C}$ using a thermostated experimental device described in detail elsewhere ${ }^{1}$. Preliminary measurements reveal that the presence of the 
fluorinated monomers increases up to an order of magnitude the permeability of oxygen with respect to pure PMMA.

The evaluation of both the molecular weights and molecular weight distributions of the fluorinated-modified materials revealed that the copolymer distribution in the linear copolymers was random and yield molecular weights between $2.1 \times 10^{6}-2.2 \times 10^{6}$ $\mathrm{g} / \mathrm{mol}$. The Mn distribution oscillated between 800,000-1,000,000 and the polydispersity was around 4.5. These values did not depend nor on the fluorinated monomer do neither on the total fluorine content in the sample, reflecting the independence of the polymerization process on the concentration of fluorine atoms present in the final matrix.

In Table 1 are collected the measured densities and refractive indexes $(\eta)$ of the different dye doped compounds studied in this work. As expected, the densities of the linear matrices, for a given MMA/fluorinated monomer volumetric proportion, increase with the number of fluorine atoms of the comonomer, corresponding to an increase in the total fluorine content of the matrix. In addition, the densities increase from linear to cross-linked matrices, and for each PFMA/cross-linked monomer volumetric proportion, increase with the number of double bonds in the functionalized monomer, indicating a progressive decrease of the free volume. However, the densities of the cross-linked matrices decrease as increase the volumetric proportion of each crosslinked monomers, reflecting the presence of residual free double bonds that remains into the matrices due to both the soft thermal conditions selected to carry out the polymerization and the steric hindrance induced by the molecular size of the pentafluororinated monomer. 
Table 1.- Glass transition temperature $\left(T_{g}\right)$, density $(\rho)$, and refractive index $(\eta)$ of the different compounds

\begin{tabular}{cccc}
\hline Material & $\operatorname{Tg}\left({ }^{\circ} \mathrm{C}\right) \pm 1$ & $\rho\left(\mathrm{g} / \mathrm{cm}^{3}\right) \pm 0.001$ & $\eta \pm 0.0005$ \\
\hline MMA/TFMA 70/30 & & 1.2468 & 1.4622 \\
MMA/PFMA 90/10 & 80 & 1.2745 & 1.4767 \\
MMA/PFMA 70/30 & & & 1.4545 \\
MMA/HFMA 90/10 & & 1.4740 \\
MMA/HFMA 70/30 & - & 1.4531 & 1.4502 \\
\hline PFMA/EGDMA 80/20 & 80 & 1.4831 & \\
PFMA/PETA 90/10 & 86 & 1.4550 & \\
PFMA/PETA 80/20 & - & 1.4326 & \\
PFMA/PETA 70/30 & 78 & 1.4851 & \\
PFMA/PETRA 90/10 & 90 & 1.4585 & \\
PFMA/PETRA 80/20 & & & \\
\hline
\end{tabular}

In Fig 1, the values of the refractive index of the materials based on MMA with different volumetric proportions of fluorinated monomer TFMA, PFMA and HFMA doped with dye PM567 are plotted as a function of the total fluorine content in the matrix. It is seen that $\eta$ decreases linearly with the increasing weight content of fluorine in the matrix. 


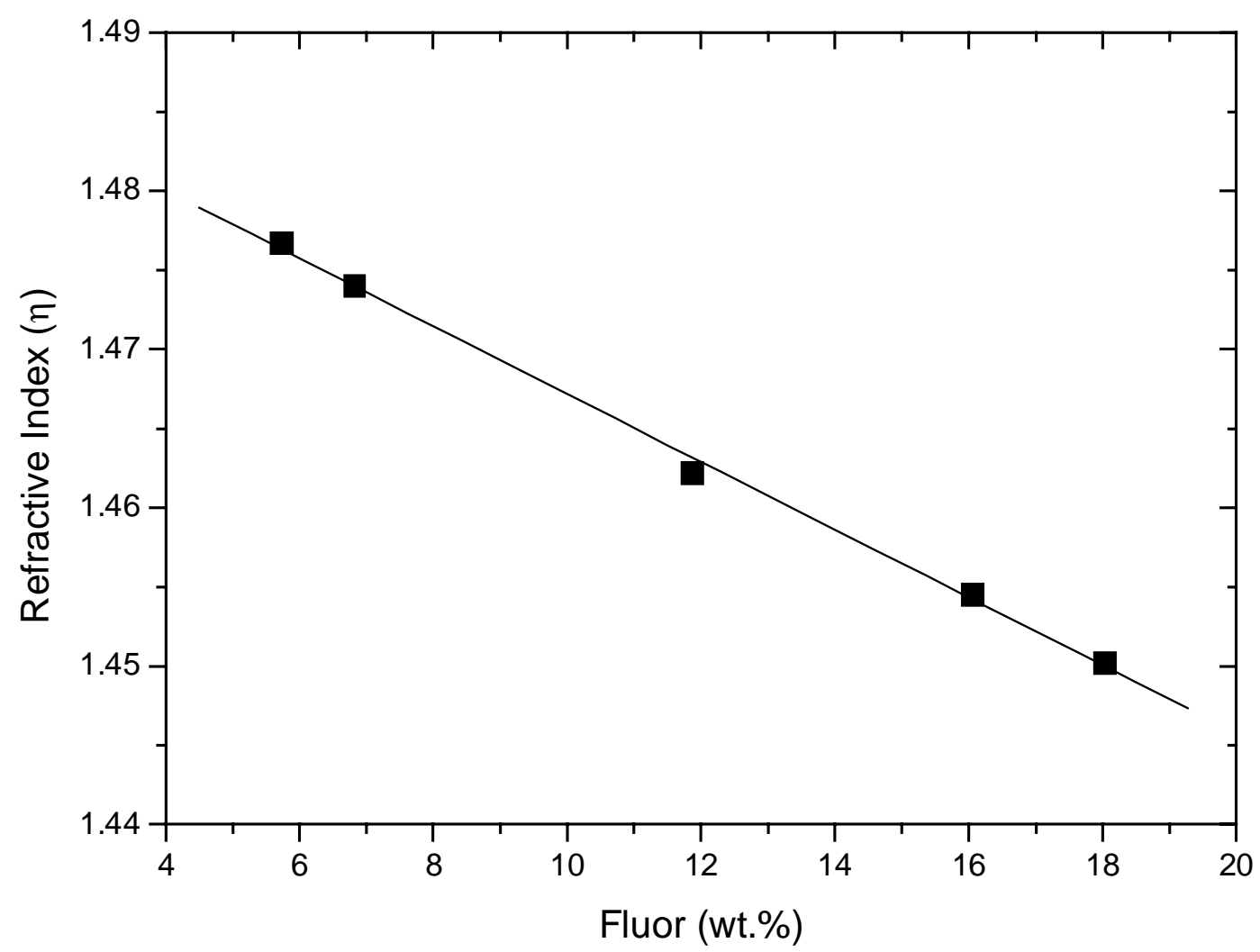

\section{Narrow-line-width laser operation}

It is well known that one of the most important features of dye lasers is their tunability, with narrow-line-width tunning ranges of tens of nanometers achieved with a single dye when a wavelength-selective resonator is utilized. Thus, the complete characterization of the herein studied dyes incorporated in fluorinated solid matrices requires an assessment of their individual tuning capabilities.

Narrow linewidth laser emission and tuning ranges of some of the dye-doped matrices were obtained by placing the samples in a home-made Shoshan-type oscillator $^{2}$, consisting of full reflecting aluminium back and tuning mirrors and a 2400 lines/mm holographic grating in grazing incidence, with outcoupling via the grating zero-order. Laser linewidth was measured with a Fabry-Perot etalon (IC Optical Systems) with free spectral range of $15.9 \mathrm{GHz}$. 
The PM567 and PM597 in fluorinated matrices emit broad-line-width laser radiation $(\mathrm{FWHM} \approx 8 \mathrm{~nm})$ in a simple plane-plane non-tunable resonator with peak wavelength in the range 560-564 nm for PM567, whereas the emission from PM597 is red shifted to the range $576-579 \mathrm{~nm}$. Thus, we chose materials of each dye to assess their tuning capability and to determine if, with just a couple of matrices in a proper tuning resonator, it would be possible to cover a wavelength region from the green to the red.

To this end, PM567 and PM597 dyes incorporated into P(MMA/PFMA 70/30) were selected and placed in a grazing-incidence grating cavity in Shoshan configuration. Tunable laser emission with line width of the order of $0.15 \mathrm{~cm}^{-1}$ and efficiency of the order of 3\% was obtained. Under these experimental conditions, a tuning range from 552 to $584 \mathrm{~nm}$ was observed for PM567 dye, while the tunability of PM597 was ranging from 565 to $602 \mathrm{~nm}$. Then, just with two fluorinated materials the region 552$602 \mathrm{~nm}$ can be continuously covered with narrow-line-width laser radiation.

\section{3.- Comparison with previous results}

For the sake of clarity, a summary of the most representative results previously obtained by other authors with these pyrrometheme complexes incorporated into polymeric and inorganic materials is presented in Table 4 . To properly compare our results with the efficiencies obtained by other authors some care should be taken because our studies have been performed under more demanding and less efficient transversal pumping conditions in a non-optimized oscillator cavity. Thus, although lasing efficiencies as high as $80 \%$ and $86 \%$, respectively, have been reported for dyes PM567 incorporated in MPMMA matrix and PM597 doped, via the sol-gel technique, a xerogel host matrix, those efficiencies were obtained under longitudinal pumping in 
optimized laser cavities and in samples with a laser grade finishing of the surfaces, which surely enhances the lasing efficiency.

Likewise, the substantial differences in experimental conditions, such as repetition rate or pumping configuration, which can strongly affect the longevity of the solid samples, makes it difficult to make a proper comparison between results obtained by different authors. To facilitate comparisons independent of an experimental setup, Rahn and $\mathrm{King}^{3}$ introduced a normalized photostability defined as the accumulated pump energy absorbed by the system per mol of dye molecules before the output energy falls to one-half its initial value. Its units are gigajoules per mol (GJ/mol). In these units the best previous results for PM567 photostability in solid matrix has been reported by Ahmad et al. ${ }^{7}$, who obtained a normalized photostability of $380 \mathrm{GJ} / \mathrm{mol}$ for PM567 doped PMMA with DABCO as chemical stabilizer. In our case, we estimate that the accumulated pump energy absorbed per mol of dye PM567 after the 100,000 pulses was $518 \mathrm{GJ} / \mathrm{mol}$ with the laser output energy remaining above its initial value when the matrix was $\mathrm{P}(\mathrm{MMA} / \mathrm{PFMA} \mathrm{70/30).} \mathrm{Pumping} \mathrm{at} 30 \mathrm{~Hz}$, the laser output of PM567 incorporated into P(PFMA/EGDMA 80/20) remained at $90 \%$ of its initial value when the accumulated pump energy was $933 \mathrm{GJ} / \mathrm{mol}$.

With dye PM597 incorporated into hybrid xerogel matrices and pumped longitudinally at $532 \mathrm{~nm}$ at $20 \mathrm{~Hz}$ repetition rate, Faloss et al. reported a drop in the laser emission of $50 \%$ of its initial value after 500,000 pump pulses ${ }^{10}$, corresponding to an accumulated pump energy of $720 \mathrm{GJ} / \mathrm{mol}$. As reported above, the laser emission of PM597 doped fluorinated lineal matrices remained about its initial value after 100,000 pump pulses, corresponding to absorbed pump energy of $1585 \mathrm{GJ} / \mathrm{mol}$. In the measurements at $30 \mathrm{~Hz}$ repetition rate, an accumulated pump energy of $12300 \mathrm{GJ} / \mathrm{mol}$ was obtained for the matrix P(MMA/HFMA 70/30), where the longest lasing lifetime 
was recorded since the laser emission remained at its initial level after 500,000 pump pulses. 


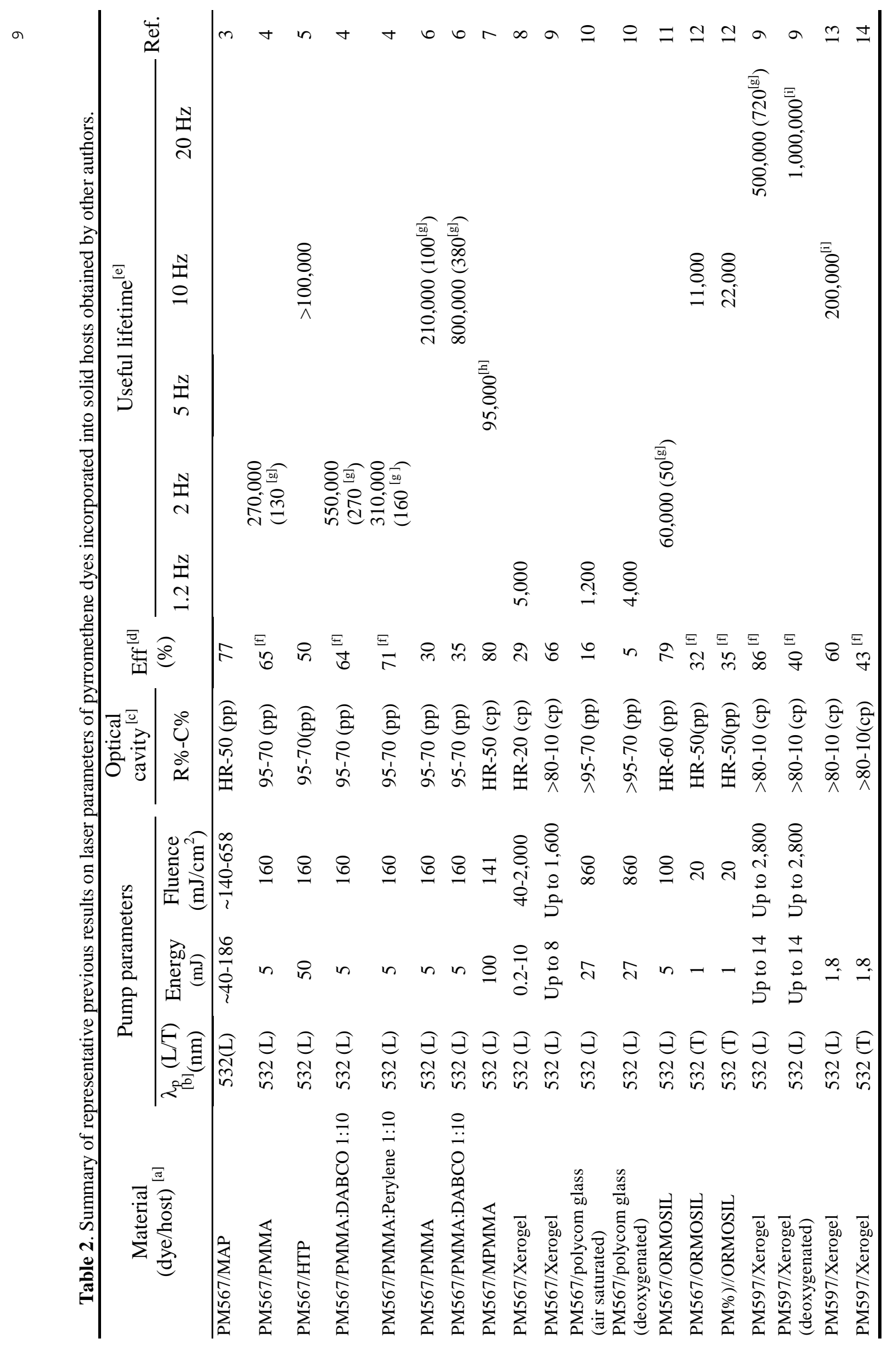




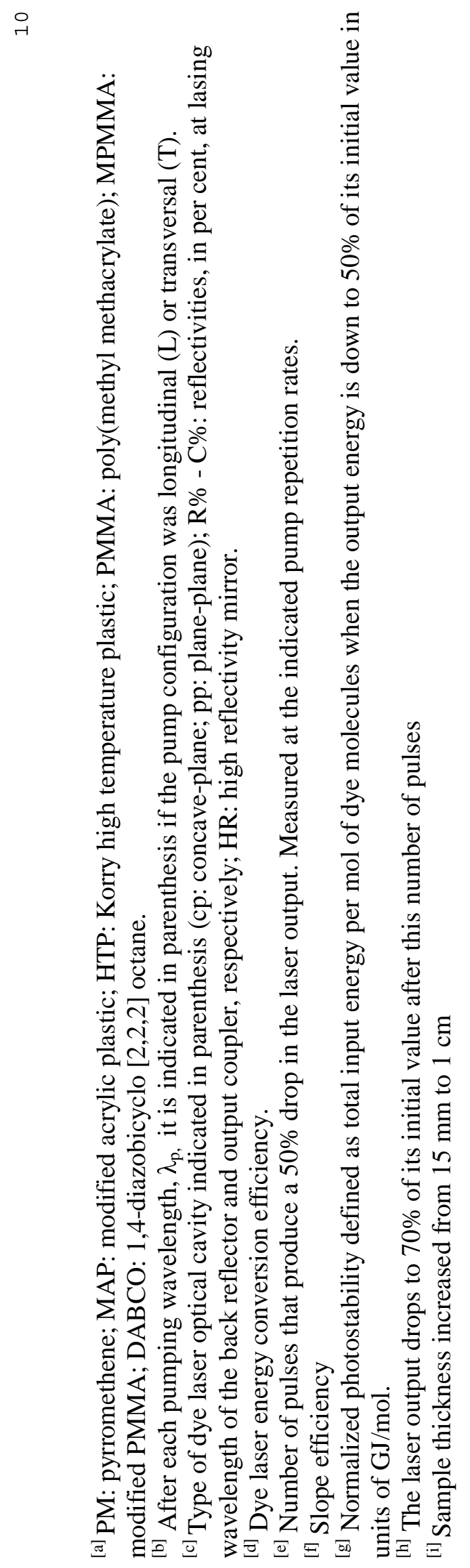




\section{References}

[1] Laguna, M.F., Saiz, E., Guzman, J., Riande, E.; Macromolecules, 1998, 31, 7488.

[2] Soshan, I., Danon, N.N., Oppenheim, U.; J. Appl. Phys.; 1977, 48, 4495.

[3] Rahn, M.D., King, T.A., Gorman, A.A., Hamblett, I., Appl. Opt.; 1997, 36, 5862.

[4] Hermes, R.H., Allik, T.H., Chandra, S., Hutchison, J.; Appl. Phys. Lett.; 1993, 63, 877.

[5] Ahmad, M., Rahn , M.D., King, T.A.; Appl. Opt.; 1999, 38, 6337.

[6] Allik, T.H., Chandra, S., Robinson, T.R., Hutchinson, J.A., Sathyamoorthi, G., Boyer, J.H.; Mater. Res. Soc. Symp. Proc.; 1994, 329, 291.

[7] Ahmad, M., King, T.A., Lo, D., Cha, B.H., Lee, J.; Opt. Commun., 2002, 203, 327.

[8] Pacheco, D., Aldag, H.R., in Solid-State lasers VII (Proc. SPIE), ed. R. Scheps, 1998, 3265, 2.

[9] Canva, M., Georges, P., Perelgritz, J.F., Brun, A., Chaput, F., Boilot, J.P.; Appl. Opt.; 1995, 34, 428.

[10] Faloss, M., Canva, M., Georges, P., Brun, A., Chaput, F., Boilot, J.P.; Appl. Opt. 1997, 36, 6760 .

[11] Rahn, M.D., King, T.A., Gorman, A.A., Hamblett, I.; Appl. Opt.; 1997, 36, 5862.

[12] Yang, Y., Wang, M., Qian, G., Wang, Z., Fan, X.; Opt. Mater.; 2004, 24, 621.

[13] Yariv, E., Reisfeld, R.; Opt. Mater.; 1999, 13, 49.

[14] Nhung, T.H., Canva, M., Dao, T.T.A., Chaput, F., Brun, A., Hung, N.D., Boilot, J.P.; Appl. Opt.; 2003, 42, 2213.

[15] Reisfeld, R., Weiss, A., Saraidarov, T., Yariv, E., Ishchenko, A.A.; Polym. Adv. Technol.; 2004, 15, 291. 